\title{
Utilization of Free Maternity Services among Reproductive Age Women of Chepang Community in Nepal
}

\author{
Shusma Acharya ${ }^{1}$, Durga Bista ${ }^{2}$ \\ ${ }^{1}$ Master in Nursing (MN) Women's Health and Development, Lecturer Manmohan Memorial Institute of Health \\ Sciences, Soalteemode Kathmandu, Nepal \\ ${ }^{2}$ Bachelor in Nursing (BN), Staff Nurse in Nepal National Hospital, Kalanki Kathmandu, Nepal \\ Corresponding Author: Shusma Acharya
}

DOI: https://doi.org/10.52403/ijhsr.20220132

\begin{abstract}
Background: Approximately 287,000 women died globally from causes related to pregnancy and childbirth in 2010. Nepal is among the countries with high maternal mortality rates in South Asia region with estimated Maternal Mortality Rate 239/100,000 live births. Underutilization of health services is one factor contributing to high maternal mortality rate. In Nepal, $81 \%$ of births take place at home without skilled health providers. Many complications related to childbirth can be prevented by utilization of maternal health services.

Methods: A descriptive cross-sectional study was carried out among 71 respondents from May 15, 2019 to November 16, 2019 and it took by using total enumeration sampling technique. Structured self developed questionnaire was used to collect data using interview technique. Data was analyzed via SPSS software version 16 by using descriptive and inferential statistics.

Results: Utilization of free maternity services was extremely low among Chepang women of Western Region of Nepal. With regards to antenatal utilization during their latest pregnancy was $73.2 \%$. Only $22.5 \%$ of the respondents had given birth of their baby in health institution rest of them delivered at home. Majority of the respondents did not utilize postnatal services (95.8\%) whereas only $4.2 \%$ respondents utilized postnatal services. There was statistically significant association between utilization of ANC services and age $(\mathrm{p}=0.000)$, income $(\mathrm{p}=.006)$, education of the respondent $(\mathrm{p}=0.001)$ and religion of the respondents $(\mathrm{p}=0.044)$. Similarly, there was statistically significant association between utilization of delivery services and age $(\mathrm{p}=0.29)$, education of the respondent $(p=0.007)$ but there is no significant association between utilization of postnatal services and selected demographic variables.

Conclusion: The study concluded that maternity services utilization is extremely low among Chepang women of Nepal. There was significant association between age, educational status and religion. Therefore, the government and non government organizations effort on health awareness programme are essential to maximize the utilization of maternity services.
\end{abstract}

Key words: Antenatal, Delivery, Chepang, Postnatal, Utilization

\section{INTRODUCTION}

Free maternity services are the services that provides during antenatal, natal and postnatal period. It also includes incentives for four ANC visit and transportation incentives for institutional delivery. A cash payment of NRs. 400 is made to women on completion of four ANC visits at the 4, 6, 8 and 9 months of pregnancy. A cash payment is made to women immediately following institutional delivery: NPR. 1,500 in mountain, NPR. 1,000 in hill and NPR. 500 in Terai region. ${ }^{[1]}$ Iron capsule and TT vaccine is provided 
during antenatal period. The maternity services are to provide safe, high-quality, accessible and equitable care to women and their families. Attendance of antenatal care, delivery in a medical setting and having a skilled health worker at delivery improve maternal health ${ }^{[1]}$.

Utilization of maternal health services vary from country to country and within the country itself in many developing countries. Access to health care services has a great deal of impacts on maternal and child survival and significantly affects mortality trends in a population. Antenatal care may play an indirect role in reducing maternal mortality by encouraging women to deliver with assistance of a skilled birth attendant or in a health facility. In most rural settings, there are challenges in increasing such health care service utilization mainly because the decisions that lead women to use the services seem to occur within the context of their marriage, household, and family. ${ }^{[2]}$

Globally, approximately 287,000 women died from causes related to pregnancy and childbirth in 2010. Of these, 162,000 were in Sub-Saharan Africa and 83,000 were in South Asia. The maternal mortality ratio ranges from 16 in the developed countries to 220 in South Asia and 500 in Sub-Saharan Africa. ${ }^{[3]}$

Globally, one-third of deliveries take place at home without skilled health workers. $^{[4]}$ The situation is worse in developing countries due to inadequate access or poor utilization of health services. In Nepal, $85 \%$ of women received antenatal check up, only $35 \%$ undergoes institutional delivery and $51 \%$ use postnatal services. ${ }^{[5]}$ The maternal mortality ratio in developing countries in 2013 was $230 / 100,000$ live births versus $16 / 100,000$ live births in developed countries. There are large disparities between countries with few countries having extremely high maternal mortality ratio around 1000/100,000 live births. There are also large disparities within countries between women with high and low income and also women living in rural and urban area ${ }^{[6]}$.

Factors that prevent women from receiving or seeking health care during pregnancy and childbirth include inadequate services, poverty, distance, lack of information, and cultural practices [7]. Underutilization of health services is one factor contributing to high maternal mortality rates, for example, $81 \%$ of births take place at home, many without skilled health providers ${ }^{[8]}$. Complications during pregnancy and childbirth such as haemorrhage, sepsis, abortion complications, pre-eclampsia and eclampsia, and prolonged/obstructed labour are the leading causes of death and disability among women of reproductive age in developing countries and millions of women still lack access to adequate skilled care during the period of pregnancy and child births ${ }^{[9]}$. All these complications can be prevented through promoting the utilization of maternal services during pregnancy, delivery and postnatal period.

The Nepal is promoting safe motherhood through maternity incentives schemes. The Safe Motherhood Programme provides essential maternity services to all women through an extensive four-tiered district health system: (i) sub-health post; (ii) health post; (iii) primary health care centre; and (iv) district hospital. In addition, there are outreach mobile clinics and female community health volunteers at the peripheral level. At the sub-health posts, maternal and child health workers provide antenatal and postnatal care and assist in home deliveries. Auxiliary nurse midwives provide antenatal and postnatal care at health posts, some of which have birthing facilities. The goal of the National Safe Motherhood Programme is to reduce maternal and neonatal morbidity and mortality and improve maternal and neonatal health through preventive and promotive activities and by addressing avoidable factors that cause death during pregnancy, childbirth and the postpartum period ${ }^{[1][5]}$. Evidence suggests that three 
delays are important factors for maternal and newborn morbidity and mortality in Nepal (delays in seeking care, reaching care and receiving care).

In Nepal, utilization of maternal health services depends on the Socio Economic Status (SES) of women. Higher SES women in terms of education level, wealth and urban residence utilize better health care services including maternity care [10]

Chepangs, also called 'Prajas', are regarded as one of the marginalized and socio-economically deprived indigenous ethnic communities living in Central and Southern Nepal especially in Chitwan, Tanahun, Gorkha and Dhading districts and also known as one of the isolated tribal groups of Nepal. Utilization of safe motherhood is deprived in women who belong to low-caste groups of Nepal. Low socioeconomic status, poor knowledge and awareness on obstetric complications, lack of decision-making autonomy, and limited health care options lead to underutilization of existing maternal health care service.

Maternal mortality reduction has also been global, regional, and national commitment, with a vital role to be played in the Agenda for Sustainable Development. Globally various program has been launched according to need of the country even though global target for reduction of maternal mortality has not met till now. In Nepal, government has launched free maternity health service with the target of reduction of maternal mortality rate but the condition has not been improved yet due to poor utilization of maternity health services. [1][5]

A community based cross-sectional survey was carried out in Euthopia. The study shows that $54 \%$ of women undergone ANC visit and only $4.1 \%$ of women delivered babies in the Institution, which is very low ${ }^{11}$. A descriptive Cross-sectional study was conducted among Chepang and Non-Chepang communities of Makawanpur and Chitwan districts of Nepal in July 2014 for assessing the antenatal and Post-natal
Check-up Practices Among Chepang and Non-Chepang Communities. In this study, out of 1250 (511 Non-Chepang and 739 Chepang), only $11.4 \%$ and $7.6 \%$ Chepang had visited health post and hospital respectively for delivery whereas $14.7 \%$ and $54.6 \%$ Non-Chepang had visited health post and hospital respectively for delivery. The practice of home based delivery is found high among the Chepang community which creates the high risk in mortality of mother and baby. $57.9 \%$ Non-Chepang followed by only $20.5 \%$ Chepang had visited four and more than four times for ANC check-up ${ }^{12}$. All these research study shows that utilization of maternity services are very low especially in indigenous group. Very few researches have been conducted in the similar community people of different places such as Chitwan and Makwanpur but only this research is not sufficient. More study is necessary to find out the actual only this research is not sufficient. More study is necessary to find out the actual marginalized group.

\section{Objectives of the study}

To find out the utilization of free maternity health services in Vyas Municipality.

To identify association between utilization of free maternity services and selected demographic variables.

\section{MATERIALS AND METHODS}

A descriptive cross-sectional study design was adopted for the study to find out the utilization of free maternity health services among reproductive age group women having at least one child up to five years. The study was conducted at Vyas municipality of Tanahau District, which is belongs to Western region of Nepal. The Study population was Reproductive age group (15-49 years) women of Chepang community having at least one child up to five years. Total enumeration sampling technique was used. The sample size was 71. Before conducting the research, formal approval was taken from Institutional Review Committee (IRC, MMIHS). Formal 
permission was taken for the data collection from Vyas Municipality of Tanahau. The researcher explained the purpose of the study to the participants and written consent was taken before data collection. Validity of the tool was maintained by consulting with the subject expert and extensive literature review before data collection. Reliability of the research instrument was done with $10 \%$ of the sample in non study population to increase the reliability of the instrument and modification of the instrument was applied as per the suggestion from pretest. Data was collected by using Self-developed structured questionnaire through face to face interview schedule within allocated time i.e. May 15, 2019 to November 16, 2019 and it took 2025 minutes for each respondent. The questionnaire was divided into two parts i.e, Socio demographic information of respondents and questions related to service utilization. Confidentiality was maintained. The data were analyzed by using SPSS version 16 where descriptive statistics (frequency, percentage, mean and standard deviation) and inferential statistics (chi square test) was used.

\section{RESULTS}

Table 1 illustrates that majority of the respondents $80.2 \%$ were between the age 15-30 years and the mean age of the respondents was 25.95 and standard deviation \pm 7.01 years. Majority of respondents $(63.4 \%)$ followed Christian religion and only $8.5 \%$ respondents and $4.2 \%$ of their spouse had secondary level education. Majority $(83.1 \%)$ of the respondents was engaged in household work and $69 \%$ of their spouses do work as a labor. Regarding income $87.3 \%$ of respondents had more than 15000 per month income $69 \%$ told that is sufficient for their fulfillment of daily needs. Majority $84.5 \%$ of respondents belonged to a nuclear family.

Table 2 shows that $71.8 \%$ of the respondents utilized ANC services. Only $22.5 \%$ and $4.2 \%$ respondents utilized delivery and postnatal services.

Table 1: Socio-Demographic Characteristics of the respondents, $\mathbf{n}=71$

\begin{tabular}{|c|c|c|}
\hline Characteristics & Frequency(n) & $\begin{array}{l}\text { Percentage } \\
(\%)\end{array}$ \\
\hline \multicolumn{3}{|l|}{ Age in years } \\
\hline $15-30$ & 57 & 80.2 \\
\hline $\begin{array}{l}>30 \\
\begin{array}{l}\text { Mean age } \\
\text { years }\end{array}\end{array}$ & 14 & 19.8 \\
\hline \multicolumn{3}{|l|}{ Religion } \\
\hline Hindu & 26 & 36.6 \\
\hline Christian & 45 & 63.4 \\
\hline \multicolumn{3}{|l|}{ Educational Status } \\
\hline Illiterate & 18 & 25.4 \\
\hline Read \& Write only & 29 & 40.8 \\
\hline Primary & 18 & 25.4 \\
\hline Secondary & 6 & 8.5 \\
\hline \multicolumn{3}{|l|}{ Spouse Education } \\
\hline Illiterate & 13 & 18.3 \\
\hline Read \& Write only & 36 & 50.7 \\
\hline Primary & 19 & 26.8 \\
\hline Secondary & 3 & 4.2 \\
\hline \multicolumn{3}{|l|}{ Occupation } \\
\hline Agriculture & 9 & 12.7 \\
\hline Household work & 59 & 83.1 \\
\hline Service & 2 & 2.8 \\
\hline Labor & 1 & 1.4 \\
\hline \multicolumn{3}{|l|}{ Occupation of spouse } \\
\hline Agriculture & 5 & 21.1 \\
\hline Business & 1 & 1.4 \\
\hline Service & 2 & 2.8 \\
\hline Labor & 49 & 69 \\
\hline Foreign employment & 4 & 5.6 \\
\hline \multicolumn{3}{|l|}{ Monthly Income } \\
\hline Up to Rs. 15000 & 9 & 12.7 \\
\hline More than Rs. 15000 & 62 & 87.3 \\
\hline \multicolumn{3}{|l|}{ Sufficiency of Income } \\
\hline Yes & 49 & 69 \\
\hline No & 22 & 31 \\
\hline \multicolumn{3}{|l|}{ Types of family } \\
\hline Nuclear & 60 & 84.5 \\
\hline Joint & 11 & 15.5 \\
\hline
\end{tabular}

Table2 Utilization of free Maternity Service $n=71$

\begin{tabular}{|l|l|l|}
\hline Variables & \multicolumn{2}{|c|}{ Utilization of Services } \\
\hline & Yes, n (\%) & No, n (\%) \\
\hline ANC service utilization & $52(73.2)$ & $19(27.8)$ \\
\hline Delivery and incentive utilization & $16(22.5)$ & $55(77.5)$ \\
\hline Postnatal service utilization & $3(4.2)$ & $68(95.8)$ \\
\hline
\end{tabular}

Table 3 Utilization of Antenatal Services $\mathbf{n}=\mathbf{7 1}$

\begin{tabular}{|l|l|l|}
\hline Variables & Frequency & Percentage \\
\hline ANC visits & & \\
\hline Yes & 52 & 73.2 \\
\hline No & 19 & 26.8 \\
\hline Reason for not visit health centre for ante partum $(\mathbf{n}=19)$ \\
\hline Lack of Knowledge & 6 & 31.6 \\
\hline Lack of time & 9 & 47.4 \\
\hline Lack of availability of health facility & 2 & 10.5 \\
\hline Not having any problem & 2 & 10.5 \\
\hline
\end{tabular}


Shusma Acharya et.al. Utilization of free maternity services among reproductive age women of Chepang community in Nepal.

\begin{tabular}{|c|c|c|}
\hline \multicolumn{3}{|c|}{ Table 3 Continued... } \\
\hline \multicolumn{3}{|c|}{ Number of ANC visit during last pregnancy $(n=52)$} \\
\hline$<4$ times & 28 & 53.85 \\
\hline$\geq 4$ times & 24 & 46.15 \\
\hline \multicolumn{3}{|c|}{ Month of ANC visit for first time $(n=52)$} \\
\hline As soon as pregnancy detected & 7 & 13.5 \\
\hline $3^{\text {rd }}$ month of pregnancy & 15 & 28.8 \\
\hline Four and later month of pregnancy & 30 & 57.7 \\
\hline \multicolumn{3}{|l|}{ ANC visit at the month of $4,6,8,9$} \\
\hline Yes & 24 & 46.15 \\
\hline No & 28 & 53.85 \\
\hline \multicolumn{3}{|c|}{ Place of antenatal visit for check up during last pregnancy $(n=52)$} \\
\hline Health post & 28 & 53.85 \\
\hline District hospital & 24 & 46.15 \\
\hline \multicolumn{3}{|l|}{ Consumption of iron/folate $(n=71)$} \\
\hline Yes & 52 & 73.2 \\
\hline No & 19 & 26.8 \\
\hline \multicolumn{3}{|l|}{ Intake of anti-helminthes $(\mathrm{n}=71)$} \\
\hline Yes & 40 & 56.3 \\
\hline No & 31 & 43.7 \\
\hline \multicolumn{3}{|l|}{ TT vaccine $(n=71)$} \\
\hline Yes & 52 & 73.2 \\
\hline No & 19 & 26.8 \\
\hline \multicolumn{3}{|l|}{ Number of TT vaccine $(n=52)$} \\
\hline One dose & 29 & 55.7 \\
\hline Two dose & 23 & 44.3 \\
\hline
\end{tabular}

Above table illustrated, $73.2 \%$ of respondents had attended an ANC clinic. Among them only $46.15 \%$ of had undergone four or more ANC visits. Reason for not visiting antenatal clinic was lack of time (47.4\%). Near about sixty percent $57.7 \%$ of the respondents had visit ANC clinic in the fourth or later months of pregnancy. All respondents prefer government hospital for ANC visit. Regarding the utilization of Iron. Folate tablet, Tetanus Toxoid injection and antihelminthes, $73.2 \%$ respondent had consumed that medication and $56.3 \%$ had received T.T injection and $56.3 \%$ had received anti-helminthes (albendazole).

Table 4 Utilization of Delivery Services, $n=71$

\begin{tabular}{|l|l|l|}
\hline Variables & Frequency(n) & Percentage (\%) \\
\hline Hospital delivery & 18 & 25.4 \\
\hline Yes & 53 & 74.6 \\
\hline No & 53 & 74.6 \\
\hline Place of delivery (n=71) \\
\hline Home & \multicolumn{1}{|l|}{} \\
\hline Government hospital & 2 & 22.5 \\
\hline Private hospital & 2.8 \\
\hline Reason for not seeking health facility (n=53) \\
\hline Long distance & 18 & 52.8 \\
\hline Lack of knowledge & 13 & 24.5 \\
\hline Traditional view of laws & 3 & 5.7 \\
\hline Shyness & 9 & 17 \\
\hline For Hospital delivery, person conducting delivery(n=18) \\
\hline Doctors & 2 & 11.1 \\
\hline Nurse/SBA & 16 & 88.9 \\
\hline Vitamin A capsule consumption(n=71) \\
\hline Yes & 18 & 25.4 \\
\hline No & 53 & 74.6 \\
\hline
\end{tabular}

Table 4 shows that last baby in home followed by only $22.5 \%$ respondent had delivered their baby in government hospital that indicate that only $22.5 \%$ utilized the free maternity health services and $74.6 \%$ respondent had delivered their baby at home that indicate the practice of home based delivery is found high among the Chepang community which creates the high chances of morbidity and mortality of mother and new born baby. The reason for not attaining hospital delivery $52.8 \%$ respondent answered there was no accessibility of health services that means away from the home. All respondents who delivered health facility received Vitamin A capsule.

Table 5 Utilization of Postnatal Services, $n=71$

\begin{tabular}{|l|l|l|}
\hline Variables & Frequency(n) & $\begin{array}{l}\text { Percentage } \\
(\%)\end{array}$ \\
\hline PNC visits(n=71) & 57 & 80.3 \\
\hline Not done & 11 & 15.5 \\
\hline$<3$ Visits & 3 & 4.2 \\
\hline$\geq 3$ visits & 11 & 78.6 \\
\hline Timing of PNC (n=14) & 2 & 14.3 \\
\hline First 24 hours & 1 & 7.1 \\
\hline Within 3-7days & \multicolumn{1}{|l|}{} \\
\hline Within 45 days & 1 & 78.6 \\
\hline Receipt of PNC services(n=14) & 7.1 \\
\hline Examination of mother and baby & 11 & 14.3 \\
\hline Contraceptives & 2 & 53.2 \\
\hline Immunization & 1 & 15.8 \\
\hline Reason for not going postnatal check up(n=57) \\
\hline Lack of knowledge & 36 & 8.8 \\
\hline Not having any complications & 9 & 12.3 \\
\hline Far from house & 5 & \\
\hline Lack of transportation & 7 & \\
\hline
\end{tabular}


Shusma Acharya et.al. Utilization of free maternity services among reproductive age women of Chepang community in Nepal.

Table 5 illustrate that majority $(80.3 \%)$ of the respondents did not utilize postnatal services among them only $(4.2 \%)$ respondents had utilized adequate number and service of postnatal. Majority $78.6 \%$ of respondents had visited postnatal services within 24 hours after delivery and minimum
7.1\% respondents had visited postnatal services at six weeks of postnatal period. Most of them $78.6 \%$ came for examination for herself and for baby. Reason for not coming postnatal service utilization respondents $53.2 \%$ answered they had no knowledge about it.

Table 6 Association between socio-Demographic variables and Utilization of ANC n=71

\begin{tabular}{|c|c|c|c|c|c|}
\hline \multirow[t]{2}{*}{ Variables } & \multicolumn{4}{|c|}{ Utilization of ANC services } & \multirow[t]{2}{*}{ P value } \\
\hline & $\begin{array}{l}\text { Yes } \\
n=51\end{array}$ & & $\begin{array}{l}\text { No } \\
n=20\end{array}$ & $(\%)$ & \\
\hline Age in years & 47 & 82.5 & 10 & 17.5 & \multirow[t]{2}{*}{$\# .000 *$} \\
\hline $15-30$ & 4 & 28.6 & 10 & 71.4 & \\
\hline \multicolumn{6}{|l|}{$>30$} \\
\hline \multicolumn{6}{|c|}{ Educational status } \\
\hline Illiterate & 7 & 38.9 & 11 & 61.1 & \multirow[t]{2}{*}{$.001 *$} \\
\hline Literate & 44 & 83.0 & 9 & 17.0 & \\
\hline \multicolumn{6}{|c|}{ Religion of Respondents } \\
\hline Hindu & 15 & 57.7 & 11 & 42.3 & \multirow[t]{2}{*}{$.044 *$} \\
\hline Christian & 36 & 80.0 & 9 & 20.0 & \\
\hline \multicolumn{6}{|c|}{ Types of family } \\
\hline Nuclear & 43 & 71.7 & 17 & 28.3 & \multirow[t]{2}{*}{$\# 1.000$} \\
\hline Joint & 8 & 72.7 & 3 & 27.3 & \\
\hline Sufficiency & & & & & \\
\hline Yes & 40 & 81.6 & 9 & 18.4 & \multirow[t]{2}{*}{$.006 *$} \\
\hline No & 11 & 50.0 & 11 & 50.0 & \\
\hline
\end{tabular}

Table 6 revealed that there was $(\mathrm{p}=0.000)$, sufficiency of the income $(\mathrm{p}=$ $.006)$, education of the respondent $(\mathrm{p}=0.001)$ statistically significant association between utilization of ANC services and age and religion of the respondents $(\mathrm{p}=0.044)$.

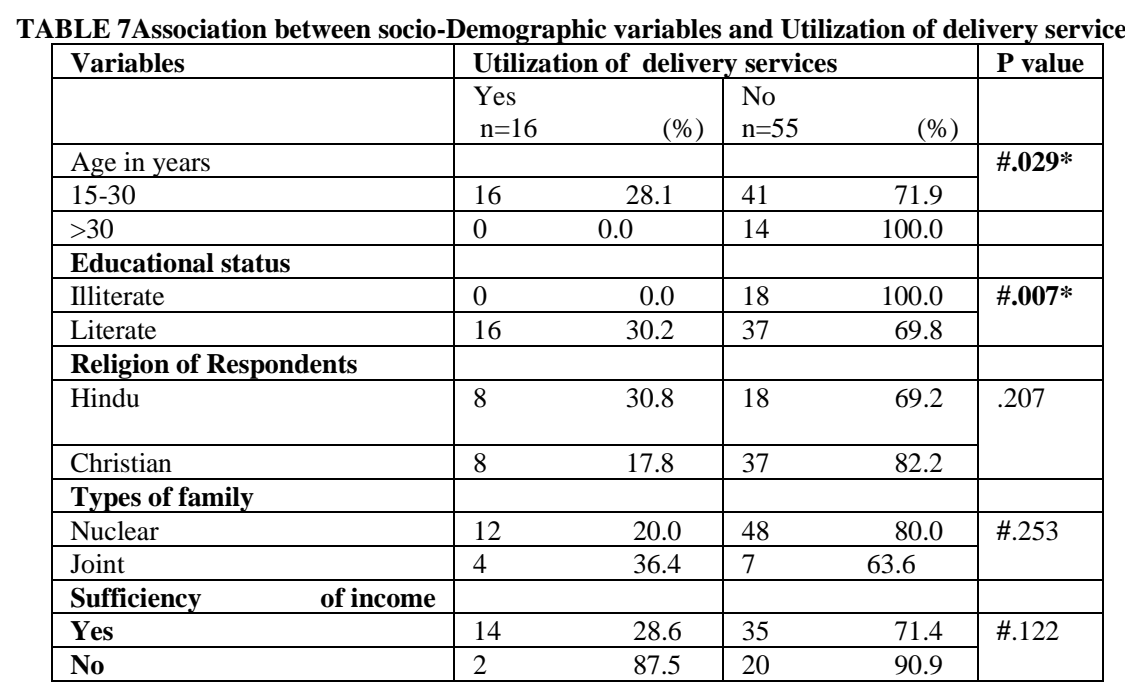

Key:* significant $(P$ value $\leq 0.05)$ and $\#=$ Fisher's Exact test.

Table 7 revealed that age $(\mathrm{p}=0.29)$, education of the respondent $(p=0.007)$ is significant with delivery service utilization.

\section{DISCUSSION}

The present study showed that out of 71 respondents, $73.2 \%$ of respondents had utilized antenatal services at their last trimester this findings is compare with study done in Lalitpur 2017, Nepal, reporting out of 153 respondents $86 \%$ of respondents had gone for ANC check-up four or more time as recommended by $\mathrm{WHO}^{13}$. The difference could be due to large sample size i.e 153 
and different sampling technique which is simple random sampling. As compare with national statistics this figure is higher than NDHS 2011 (58.3\%) and lower than NDHS $2016(84 \%) .^{[14][15]}$ This may be due to large sample size i.e 12,862 reproductive age women were interviewed and different sampling technique was used. This study reveals that only $22.5 \%$ respondents had utilized the free delivery services and $77.5 \%$ respondents had not utilized the delivery services. Similar study conducted in Chitawan and Makwanpur district in 2014 Chepang community shows that only $3.7 \%$ had utilized the delivery services and $96.3 \%$ Chepang women did not utilized such services $^{12}$. This may be due to lack of knowledge about free maternal health services, inaccessibility free maternal services, poor decision power of women etc. Similarly, the utilization of postnatal services, study shows that only $4.2 \%$ of respondents utilized the postnatal services with an accurate visit. This study is contracted with study done by NDHS 2016 which is $57 \%^{15}$. This may be due to large sample i.e. 12,862 and different sampling technique.

In regards to number of ANC visit, $46.15 \%$ had attended four or more than four visit at accurate month that is 4,6,8 and 9 which is recommended by WHO, among them all respondents had chosen government health facility for place of ANC visit either it is health post or district hospital. As compare to study conducted in Ethiopia shows $46.5 \%$ answered they attended more than four antenatal visits which is similar to this study but $86.5 \%$ respondent had chosen public health facility for antenatal checkup. ${ }^{11}$ Similarly among 71 respondents, $73.2 \%$ respondents had taken iron/folate tablets and Tetanus Toxid injection but only $56.3 \%$ respondents had taken antihelminth medication. Contradict with the findings of the study conducted in Nigeria $201394.1 \%$ respondents received iron/folic acid tablet, $87.9 \%$ respondents received Tetanus Toxoid injection ${ }^{[12]}$. This may be due to large sample size i.e 405 and multistage sampling technique another reason of these differences may be majority of respondents were literate and employed.

Nepal government has developed different policies to promote the institutional delivery although the result has not been improved. This study revealed that majority $74.6 \%$ delivery had take place at home. Compare to similar study conducted in Chepang women at Makawanpur and Chitawan $96.3 \%$ had given birth at home ${ }^{13}$. This may be lack of knowledge about free maternity health services, poor decision making power of women, and inaccessibility of health services that mean away from the home. On area of postnatal service utilization only $19.7 \%$ respondents had attended postnatal visit, among them only $4.2 \%$ had done more than three visit which is recommended number for visit. Compare with study conducted by NDHS 2016 which is not similar i.e $57 \%{ }^{15}$. This may be due to large sample size, different study setting and sampling technique. Types of service utilization $78.6 \%$ respondents came for examination of mother and baby.

The present study findings reveal that there was statistically significant between age, educational level, family income and religion with utilization of the antenatal services. Consistent to cross sectional study carried out in slums of Pokhara Sub-Metropolitan city, Nepal reflects that utilization of antenatal services is significantly associated with age of the respondents. ${ }^{16}$. This study also reveals that there was statistically significant between age and educational level with delivery services utilization. Compare with the study conducted in Euthopia shows that there was statistically significant between marital status, education, proximity of health facility to the village, and husband's occupation, while use of institutional delivery was mainly associated with parity, education, having received ANC advice, a history of difficult/prolonged labour, and husbands' occupation. 


\section{CONCLUSION}

It is concluded that utilization of Antenatal services is relatively acceptable as compared to utilization of Delivery and Postnatal services among Chepang women of Vyas municipality. There was significant association between utilization of antenatal services with respondents Age, types of family and sufficiency of income. Despite the provision of free maternal health care services provided by Government of Nepal utilization of these services among such indigenous group is still low. Hence improving the quality of Antenatal Care through the provision of proper counseling and advice to Antenatal Care attendants might increase the rate of institutional delivery and postnatal visit.

\section{Acknowledgement: None}

\section{Conflict of Interest: None}

\section{Source of Funding: None}

\section{Ethical Approval: Approved}

\section{REFERENCES}

1. Annual report.2018 Kathmandu. Nepal: Department of health services, Ministry of health and population2019.

2. Parkhurst JO, Ssengooba F. Assessing access barriers to maternal health care: measuring bypassing to identify health centre needs in rural Uganda. Health policy and planning. 2009 Sep 1;24(5): 377-84.

3. Nyongesa $\mathrm{C}, \mathrm{Xu} \mathrm{X}$, Hall JJ, Macharia WM, Yego F, Hall B. Factors influencing choice of skilled birth attendance at ANC: evidence from the Kenya demographic health survey. BMC pregnancy and childbirth. 2018 Dec;18(1):1-6.

4. World Health Organization. WHO antenatal care recommendations for a positive pregnancy experience: nutritional interventions update: vitamin D supplements during pregnancy.
5. Annual report.2011 Kathmandu. Nepal: Department of health services, Ministry of health and population 2012 .

6. World Health Organization. Trends in maternal mortality: 1990-2015: estimates from WHO, UNICEF, UNFPA, World Bank Group and the United Nations Population Division. World Health Organization; 2015.

7. Ho CW, Caals K. People-centred universal health coverage in the AsiaPacific. Asian Bioethics Review. 2019 Mar;11(1):1-3.

8. Demographic N. Health Survey. 2006. Kathmandu, Nepal. Ministry of Health and Population.2007 New ERA, and Macro International Inc.

9. WHO U. UNFPA, World Bank. Maternal mortality in 2005: estimates developed by WHO, UNICEF.

10. Baral YR, Lyons K, Skinner J, van Teijlingen ER. Maternal health services utilisation in Nepal: Progress in the new millennium? Health science journal. 2012 Oct 1;6(4):618.

11. Wudineh KG, Nigusie AA, Gesese SS, Tesu AA, Beyene FY. Postnatal care service utilization and associated factors among women who gave birth in Debretabour town, North West Ethiopia: a community-based cross-sectional study. BMC pregnancy and childbirth. 2018 Dec;18(1):1-9.

12. Ghimire M, Maharjan RK. Antenatal and Post-natal Check-up Practices Among Chepang and Non-Chepang Communities of Nepal. Journal of Advanced Academic Research. 2014; 1(2): 64-73.

13. Ghimire N,Khatry R,Shakya V.Maternal Health Services Utilization among Mothers in a Rural Municipality. Journal of Patan Academy of Health Sciences. 2021 Apr;8(1):121-31.

14. Demographic N. Health Survey 2011 Kathmandu. Nepal: Ministry of Health and Population. 2012. New ERA, and Macro International Inc.

15. Demographic N. Health Survey 2016 Kathmandu. Nepal: Ministry of Health 
Shusma Acharya et.al. Utilization of free maternity services among reproductive age women of Chepang community in Nepal.

and Population. 2017. New ERA, and Macro International Inc.

16. Adewoye KR, Musa IO, Atoyebi OA, Babatunde OA. Knowledge and utilization of antenatal care services by women of child bearing age in IlorinEast local government area, North Central Nigeria. International Journal of Science and Technology. 2013 Mar; 3(3): 17-22.

17. Sharma D, Pokharel HP, Budhathoki SS, Yadav BK, Pokharel PK. Antenatal
Health Care Service utilization in slum areas of Pokhara sub-metropolitan city, Nepal. Journal of Nepal Health Research Council. 2016 Jun 6.

How to cite this article: Acharya S, Bista D. Utilization of free maternity services among reproductive age women of Chepang community in Nepal. Int J Health Sci Res. 2022; 12(1): 236-244. DOI: https://doi.org/ 10.52403/ijhsr.20220132 